\title{
Sivas 4 Eylül Barajı Su Kalitesi-Seviye İlişkisinin Coğrafi Bilgi Sistemi (CBS) İle Haritalanması
}

\author{
*15ayiter Yıldız, ${ }^{2}$ Can Bülent Karakuş \\ ${ }^{1}$ Cumhuriyet Üniversitesi, Çevre Mühendisliği Bölümü, Mühendislik Fakültesi, Sivas \\ sayiteryildiz@gmail.com \\ ${ }^{2}$ Cumhuriyet Üniversitesi, Şehir ve Bölge Planlama Bölümü, Mimarlık Fakültesi, Sivas \\ sayiteryildiz@gmail.com
}

Geliş Tarihi: 2017-01-22 Kabul Tarihi: 2017-01-31

\section{$\ddot{O} z$}

Göl ve barajlara gelen ve buradan çıkan kirletici yüklerin oluşturacağı etki, uzun bir zaman dilimi içinde ortaya çıkmaktadır. Su ortamlarında kirlenmeyi belirleyen belli başlı kriterler fizikokimyasal ve biyolojik faktörlerdir. Bir suda yaşayan canlıların biyolojik çeşitlilik, besin zinciri, su kalitesi ve suyun biyolojik yönden temizlenmesi gibi faktörler açısından büyük bir önemi vardır. Son yıllarda baraj göllerinin fiziko-kimyasal özelliklerinin incelendiği çalışmalar artış göstermiştir.

Bu çalışmada; Sivas kentinin içme suyu ihtiyacının karşılandığı 4 Eylül Barajı'nın 12 farklı noktasında her 5 m'de bir numune alınmıştır. Bu numunelerde sıcaklık, EC (Elektriksel iletkenlik), çözünmüş oksijen (Ç.O), pH, bulanıklık, mangan (Mn), demir (Fe), NO3 (Nitrat) ve organik madde analizleri yapılmıştır. Bu analizler ile birlikte barajda seviyeye bağlı su kalitesi belirlenmiştir. Elde edilen analiz sonuçları, CBS'nin analiz yöntemlerinden olan Kriging enterpolasyon yöntemi ile değerlendirilmiş ve barajın farklı derinliklerindeki su kalitesine ait mekânsal dağılım haritaları oluşturulmuştur. Çalışmadan elde edilen sonuçlara göre; mangan değerinin derinlik arttıkça arttığ 1 , Fe değerinin ise önemli bir değişiklik göstermediği belirlenmiştir. Organik madde miktarının yüzeyde çok fazla iken belli bir derinlikten sonra çok fazla değişmediği, ayrıca derinliğe bağlı olarak pH değerinin de değişim göstermediği belirlenmiştir. Ölçülen NO3 değerleri 0.1-0.3 mg/L arasında değişirken çözünmüş oksijen değerlerinde önemli bir değişiklik gözlenmemiştir. Bulanıklık gölün tabanına doğru oldukça artmıştır. EC değerinin ise derinlikle önemli bir değişim göstermediği, göl kenarlarındaki EC değerlerinin gölün orta kısmına göre daha yüksek değerlerde olduğu belirlenmiştir.

Anahtar Kelimeler: İçme suyu baraj1, seviye-kalite ilişkisi, CBS, organik madde, EC

\section{Mapping of Water Quality-Level Relation of Sivas 4 Eylül Dam With Geographic Information System (GIS)}

\author{
${ }^{* 1}$ Sayiter Y1ldız, ${ }^{2}$ Can Bülent Karakuş \\ ${ }^{1}$ University of Civil Engineering, Department of Environmental Engineering, Faculty of Engineering, Sivas \\ sayiteryildiz@gmail.com \\ ${ }^{2}$ Computer University, Department of City and Regional Planning, Faculty of Architecture, Sivas \\ sayiteryildiz@gmail.com
}

\begin{abstract}
The effect of pollutant loads coming from and coming out of lakes and dams arises over a long period of time. The main criteria that determine contamination in aquatic environments are physicochemical and biological factors. Biodiversity, nutrient chain, water quality and the cleanliness of water from the biological side are all important factors in living an aquatic life. In recent years, the studies on the physico-chemical properties of dam lakes have increased.

In this study; a sample was taken every $5 \mathrm{~m}$ from 12 different points of the 4th September Dam where the drinking water of Sivas city is met. These samples were analyzed for temperature, EC (electrical conductivity), dissolved oxygen, $\mathrm{pH}$, turbidity, manganese, iron, NO3 (nitrate) and organic matter. With these analyzes, water quality related to the level at the dam was determined. The obtained analysis results were evaluated by Kriging interpolation method which is one of the analysis methods of GIS and spatial distribution maps of water quality at different depths of the dam were created. According to the results obtained without working; It was determined

*Sorumlu Yazar: Cumhuriyet Üniversitesi, Çevre Mühendisliği Bölümü, Mühendislik Fakültesi, Sivas sayiteryildiz@gmail.com
\end{abstract}

Doi: 10.21541/apjes.337111 
that manganese value increased with increasing depth and Fe value did not show any significant change. It has been determined that the amount of organic matter does not change much after a certain depth while it is too much on the surface, and it does not change in $\mathrm{pH}$ value depending on the depth. The measured NO3 values ranged from 0.1 to $0.3 \mathrm{mg} / \mathrm{L}$, but no significant change in dissolved oxygen values was observed. The turbidity has increased considerably towards the bottom of the lake. It was determined that the EC values did not show a significant change and the EC values at the edge of the lakes were higher than the middle part of the lake.

Keywords: Drinking water dam, level-quality relation, GIS, organic matter, EC

\section{GíRiș}

İçilebilir su kaynaklarının sorumsuzca kirletilmesi, geri dönüşümü olanaksız sorunların yaşanmasına zemin hazırlamaktadır. Tahminler, artan su ihtiyacı ile giderek azalan temiz su kaynağı eğrilerinin 2030 yılında kesişeceğini göstermektedir [1]. Bu yüzden alternatif su kaynaklarının belirlenmesi ve korunması oldukça önemlidir.

Yüzey suyu kaynakların kullanımını belirlerken su kaynağının fiziksel, kimyasal ve biyolojik özelliklerini bilmek çok önemlidir. Bu amaçla ülkemizde birçok çalışma yapılmaktadır [2-3].

Nehir barajı taşkın kontrolü, sulama, içme suyu temini ve hidroelektrik üretimi de dahil olmak üzere önemli toplumsal ve ekonomik faydalar sağlar [4-5]. Ancak doğal nehir ekosistemleri üzerinde ciddi etkiler yaratır [6]. Nehirlerin baraj göl alanına dönüşmesi fiziksel değişikliklere, termal tabakalaşmaya ve kültürel ötrofikasyona neden olabileceği gibi hidrolojik ve ekolojik değişikliklere de neden olabilir [7].

Göller oldukça büyük arazi parçalarının drenaj sularını aldıklarından göl ve gölü çevreleyen kara arasında sürekli bir alışveriş vardır. Yüzey ve yüzey altı akışları göle girer ve çıkar. Bu akışlar da çeşitli fiziksel, kimyasal ve biyolojik bileşenleri, organik maddeleri, tortu ve diğer pek çok maddeyi beraberinde sürükler [8]. Göl ve barajlara gelen ve buradan çıkan kirletici yüklerin oluşturacağı etki, uzun bir zaman dilimi içinde ortaya çıkmaktadır.

Yüzey sularında gözlenen kirlilik noktasal ve yayılı olmak üzere ikiye ayrılmaktadır. Noktasal kaynaklı kirlilik atıksuyun tek bir noktadan deşarj edilmesi ile oluşur [9]. Yayılı kirlilik ise meteorolojik olaylara ve arazinin yapısına bağlı olarak farklı zaman dilimlerinde geniş alanlardan geçerek alıcı ortama ulaşan kirleticilerin oluşturduğu kirlilik türüdür [10]. Yayılı kirliliği oluşturan suların yapısı iklime, yüzey şekline, hidrolojiye, arazi kullanımına ve toprağın yapısına bağlı olduğundan yayılı kirliliğin tespiti ve kontrolü çok daha zordur [11].
Su kalitesinde meydana gelen mevsimsel ve mekânsal değişiklikler ortaya koyulabilmesine rağmen değişime neden olan etmenler tam olarak belirlenememektedir. Su ortamlarında kirlenmeyi belirleyen belli başlı kriterler fizikokimyasal ve biyolojik faktörlerdir. Bir suda yaşayan canlıların biyolojik çeşitlilik, besin zinciri, su kalitesi ve suyun biyolojik yönden temizlenmesi gibi faktörler açısından büyük bir önemi vardır. Son y1llarda baraj göllerinin fiziko-kimyasal özelliklerinin incelendiği çalışmalar artış göstermiştir [12-13]. Bu amaçla baz alınan öncelikli fiziksel parametreler; askıdaki katı maddeler, yüzücü maddeler, kolloidal maddeler, bulanıklık, renk, tat, sicaklık ve elektriksel iletkenlik olarak sıralanabilir [14].

Bilgisayar destekli veri analizi ve görselleştirme araçları; su kaynaklarının korunması, geliştirilmesi ve yönetimi çalışmalarında önemli rol oynamaktadır. Özellikle Coğrafi Bilgi Sistemleri (CBS) son yıllarda oldukça yaygın olarak kullanılmaktadır. Bu amaçla su kalitesi ve kirliliği izleme çalışmalarında CBS yardımıyla analiz edilmiş mekânsal dağılım haritaları ortaya koyulmaya başlanmıştır [15].

$\mathrm{Bu}$ çalışmada; Sivas kentinin içme suyu ihtiyacının karşılandığı 4 Eylül Barajı'nın farklı noktalarından ve farklı derinliklerde numuneler alınarak, barajda seviyeye bağlı su kalitesinin belirlenmesi amaçlanmıştır. Ayrıca elde edilen analiz sonuçları, CBS'nin analiz yöntemlerinden olan Kriging enterpolasyon yöntemi ile değerlendirilmiş ve barajın farklı derinliklerindeki su kalitesine ait mekânsal dağılım haritaları oluşturulmuştur.

\section{YÖNTEM}

$\mathrm{Bu}$ çalışma Sivas kenti içme suyu ihtiyacının karşıladığı 4 Eylül Barajı'nda yürütülmüştür. Sivas 4 Eylül Barajı, Sivas kentinin içme suyu ihtiyacını karşılamak üzere Sivas'ın $10 \mathrm{~km}$ kuzeydoğusunda, Yukarı Kızılırmak Havzasında Mismıl Irmağı üzerinde yer alan bir içme suyu barajıdır. Baraj 236,8 km2 drenaj alanına sahiptir. Baraj1 besleyen Mismıl Irmaktan başka yan dereler de mevcuttur. Bu derelerden gelen sular, baraj göl alanını beslemektedir. 4 Eylül Barajı'nın 
koruma alanları ve beslenim havzası Şekil 1' de verilmiştir [16]. Sivas kentinin içme ve kullanma suyu ihtiyacının yaklaşık \% 49'luk kısmı 400-550 lt/sn'lik debiyle Tavra havzasında bulunan kuyulardan, \% 51'lik kısmı da 4 Eylül Barajı'ndan karşılanmakta olup; günlük ihtiyaç mevsim şartlarına göre 800-1100 lt/sn arasında değişmektedir.

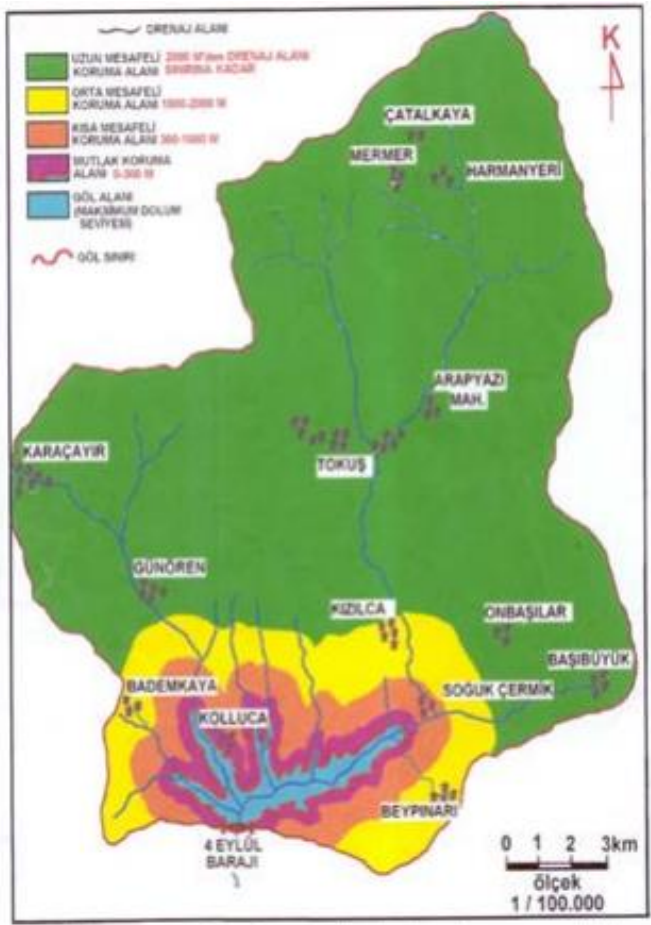

Şekil 1. 4 Eylül Barajı ve beslenim alanı

$\mathrm{Bu}$ çalışma kapsamında 4 Eylül Barajı göl alanında tüm barajı temsil edecek şekilde 12 farklı noktada yüzeyden ve her $5 \mathrm{~m}$ derinlikte bir numune alınarak analizler gerçekleştirilmiştir. Baraj gölalanı üzerinde numune alınan noktalar Şekil 2'de görülmektedir.

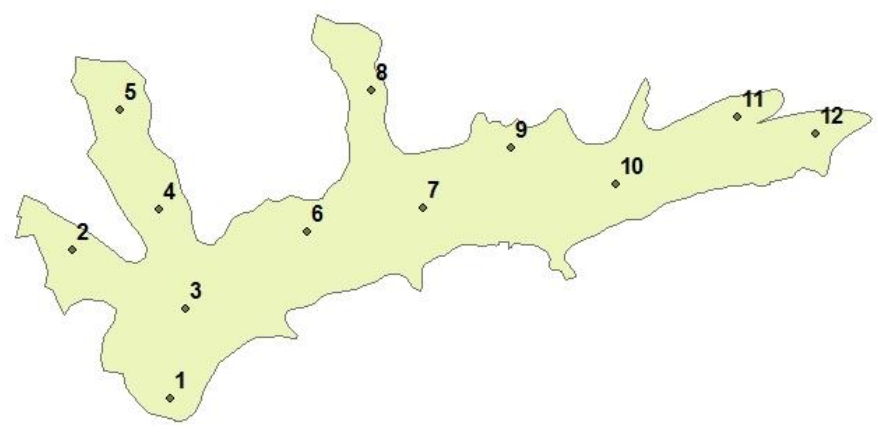

Şekil 2. 4 Eylül barajı üzerinde numune alınan yerlerin noktasal gösterimi

$\mathrm{Bu}$ numunelerde sicaklık, bulanıklık, Ç.O, organik madde, $\mathrm{pH}, \mathrm{EC}, \mathrm{Mn}, \mathrm{Fe}$ ve $\mathrm{NO} 3$ analizleri yapılmıştır. Fiziksel ve kimyasal analizler su analizlerinde geçerli metot olan "Standart Metotlar"a [17] göre yapılmıştır. Sıcaklık, bulanıklık, Ç.O ve organik madde analiz sonuçları CBS'nin analiz yöntemlerinden olan Kriging enterpolasyon yöntemi ile değerlendirilmiş ve barajın farklı derinliklerindeki su kalitesine ait mekânsal dağılım haritaları oluşturulmuştur. Sicaklık, pH ve EC ölçümleri çoklu ölçüm aparatı kullanılarak yerinde yapılmıştır. $\mathrm{Bu}$ iki parametrenin dışındaki diğer parametrelerin analizleri ise laboratuar ortamında yapılmıştır. 


\subsection{Kriging Enterpolasyon Yöntemi}

Kriging, çok güçlü ve hassas olarak interpolasyon sağlayan bir yöntemdir. Bilinmeyen bir değeri hesaplarken tüm örneklemlerin değerlerini kullanır. Kriging yöntemi çok aşamalı bir süreçtir, öncelikle örneklem noktalarının keşfi istenir, ardından bu örneklem noktalarına uygun olarak tahmini bir yüzey modeli belirlenir ve bu yüzeyi değerlendirmek gerekir [18]. Kriging işlemi iki aşamalı olarak gerçekleşir. İlk aşamada, verilerin mekânsal yapısı hesaplanır ve ikinci aşamada ise tahmin edilen bir yüzey oluşturulur. Kriging yöntemi; belli bir konum için bilinmeyen bir değeri tahmin etmek için mekânsal veri ilişkisi ve tahmin edilen konum etrafindaki bilinen noktaların değerlerini kullanır [19]. Kriging yöntemi, ölçülmemiş bir konum için bir tahmin oluşturmak için çevresindeki ölçülen değerleri ağırlıklandırdığ 1 için verilerin ağıllıklı bir toplamı olarak eşitlik 1'de ifade edilmektedir [20].

$$
\hat{Z}\left(s_{0}\right)=\sum_{i=1}^{N} \lambda_{i} Z\left(s_{i}\right)
$$

Burada; $\mathrm{Z}(\mathrm{Si})=$ i lokasyonundaki ölçülen değer, $\lambda \mathrm{i}=\mathrm{i}$ lokasyonundaki ölçülen bir değer için bilinmeyen bir ağırlık, $\mathrm{S} 0=$ tahmin edilen lokasyon, $\mathrm{N}$ = ölçülen değerlerin sayısıdır.

Çalışma kapsamında; elde edilen su kalitesi analiz sonuçlarının CBS ortamında analiz edilebilmesi ve değerlendirilebilmesi için ArcGIS 10.2 yazılımı kullanılmıştır. Çalışmanın amacına uygun olarak çalışma kapsamında kullanılan tüm veriler aynı koordinat sistemine (UTM/ED50) dönüştürülmüsştür. Numunelerde yerinde ölçümü yapılan $\mathrm{pH}$ ve EC parametreleri için elektrometrik (potansiyometrik) HACH HQ30 D marka cihaz kullanılırken, laboratuarda analizi yapılan bulanıklık parametresi için türbidimetrik $\mathrm{HACH}$ 2100 Q marka cihaz; $\mathrm{Fe}, \mathrm{Mn}$ ve NO3parametreleri için ise spektrofotometrik $\mathrm{HACH}$ DR 5000 marka cihaz kullanılmıştır.

\section{BULGULAR VE TARTIŞMA}

Baraj göl alanının 12 farklı noktasından alınan numunelerde sıcaklık, organik madde, bulanıklık, Ç.O, $\mathrm{pH}, \mathrm{EC}$, nitrat, demir ve mangan analizleri yapılmış olup sonuçlar Tablo 1'de verilmiştir. Ayrıca farklı derinliklerdeki sıcaklık (Şekil 3), bulanıklık (Şekil 4), Ç.O (Şekil 5) ve organik madde (Şekil 6) açısından su kalitesine ait mekânsal dağılım haritaları oluşturulmuştur.

Tablo 1. Numune alınan noktalarda derinliğe bağlı su kalitesi değerleri

\begin{tabular}{|c|c|c|c|c|c|c|c|c|c|c|c|c|}
\hline $\begin{array}{l}\text { Parametre/ } \\
\text { Derinlik (m) }\end{array}$ & 1 & 2 & 3 & 4 & 5 & 6 & 7 & 8 & 9 & 10 & 11 & 12 \\
\hline \multicolumn{13}{|l|}{ Sicaklık $\left(C^{0}\right)$} \\
\hline Yüzey & 17.5 & 19.2 & 16.7 & 17.2 & 19.6 & 17.4 & 18 & 19 & 18.1 & 18.6 & 20.1 & 20.3 \\
\hline 5 & 16.1 & 18.3 & 16.4 & 17.3 & 18.1 & 17.1 & 17.6 & 17.3 & 16.8 & 17.7 & 17.3 & 17.3 \\
\hline 10 & 15.9 & 17.8 & 16.3 & 15.8 & - & 16.5 & 16.5 & 16.8 & 17.3 & 17.6 & - & - \\
\hline 15 & 15.3 & - & 15.1 & 15.5 & - & 15.2 & 15.7 & - & 16.7 & 15.5 & - & - \\
\hline 20 & 15.7 & - & 15.3 & 15.1 & - & 15 & 14.3 & - & 15.7 & 14.1 & - & - \\
\hline 25 & 14 & - & 14.7 & 14.9 & - & 13.8 & 13.9 & - & - & 12.6 & - & - \\
\hline 30 & - & - & 13.6 & - & - & 12 & 11.3 & - & - & 11.4 & - & - \\
\hline 35 & - & - & 10.6 & - & - & 10.4 & 10.8 & - & - & - & - & - \\
\hline 40 & - & - & 10.1 & - & - & 10.2 & - & - & - & - & - & - \\
\hline \multicolumn{13}{|c|}{ Bulanıklık (NTU) } \\
\hline Yüzey & 1.57 & 1.83 & 1.45 & 1.83 & 1.26 & 2.02 & 1.51 & 1.83 & 4.7 & 1.66 & 4.7 & 5.8 \\
\hline 5 & 3.8 & 1.82 & 1.4 & 1.8 & 1.93 & 1.79 & 1.35 & 1.82 & 3.89 & 2.13 & 4.1 & 4.7 \\
\hline 10 & 2.45 & 2.13 & 2.23 & 2.1 & - & 1.65 & 1.35 & 2.12 & 1.43 & 1.3 & - & - \\
\hline 15 & 2.3 & - & 3.04 & 1.13 & - & 1.35 & 1.06 & - & 2.42 & 1.01 & - & - \\
\hline 20 & 1.42 & - & 1.46 & 1.38 & - & 1.4 & 1.37 & - & 1.37 & 1.43 & - & - \\
\hline 25 & 1.54 & - & 1.71 & 1.75 & - & 1.48 & 1.59 & - & - & 1.42 & - & - \\
\hline 30 & - & - & 1.48 & - & - & 1.67 & 1.8 & - & - & 3.17 & - & - \\
\hline 35 & - & - & 1.58 & - & - & 2.12 & 3.08 & - & - & - & - & - \\
\hline 40 & - & - & 12.9 & - & - & 15.8 & - & - & - & - & - & - \\
\hline \multicolumn{13}{|l|}{ Ç.O (mg/L) } \\
\hline Yüzey & 7.45 & 8.4 & 7.78 & 9.4 & 5.5 & 7.84 & 4.92 & 9.4 & 7.45 & 7.93 & 9.4 & 9.1 \\
\hline 5 & 5.38 & 6.73 & 7.63 & 7.73 & 5.43 & 7.54 & 5.17 & 6.73 & 5.38 & 8.04 & 7.73 & 7.2 \\
\hline 10 & 5.95 & 7.1 & 7.41 & 7.1 & - & 8.27 & 5.11 & 7.1 & 4.95 & 8.19 & - & - \\
\hline 15 & 6.62 & - & 7.28 & 7.82 & - & 8.32 & 6.09 & - & 5.62 & 8.67 & - & - \\
\hline 20 & 7.03 & - & 7.74 & 8.08 & - & 7.68 & 6.31 & - & 6.03 & 8.74 & - & - \\
\hline
\end{tabular}




\begin{tabular}{|c|c|c|c|c|c|c|c|c|c|c|c|c|}
\hline 25 & 7.65 & - & 7.96 & 8.4 & - & 7.99 & 6.4 & - & - & 8.65 & - & - \\
\hline 30 & - & - & 8.35 & - & - & 8.62 & 8.02 & - & - & 8.52 & - & - \\
\hline 35 & - & - & 8.84 & - & - & 8.26 & 7.75 & - & - & - & - & - \\
\hline 40 & - & - & 8.39 & - & - & 8.45 & - & - & - & - & - & - \\
\hline \multicolumn{13}{|c|}{ Organik madde (mg/L) } \\
\hline Yüzey & 0.8 & 1.2 & 0.9 & 0.6 & 0.8 & 0.7 & 0.8 & 1 & 0.8 & 0.7 & 1.5 & 1.3 \\
\hline 5 & 0.5 & 0.9 & 0.6 & 0.8 & 0.9 & 0.8 & 0.9 & 0.8 & 0.6 & 0.8 & 1.2 & 1.2 \\
\hline 10 & 0.4 & 1 & 0.6 & 0.7 & - & 0.8 & 0.8 & 1 & 0.6 & 0.7 & - & - \\
\hline 15 & 0.6 & - & 0.6 & 0.4 & - & 0.8 & 0.9 & - & 0.6 & 0.5 & - & - \\
\hline 20 & 0.6 & - & 0.4 & 0.7 & - & 0.8 & 0.8 & - & 0.8 & 0.4 & - & - \\
\hline 25 & 0.6 & - & 0.8 & 0.6 & - & 0.7 & 0.8 & - & - & 0.6 & - & - \\
\hline 30 & - & - & 0.7 & - & - & 0.6 & 0.7 & - & - & 1.1 & - & - \\
\hline 35 & - & - & 0.6 & - & - & 0.9 & 1.1 & - & - & - & - & - \\
\hline 40 & - & - & 1 & - & - & 1 & - & - & - & - & - & - \\
\hline \multicolumn{13}{|l|}{ pH } \\
\hline Yüzey & 7.74 & 7.71 & 7.5 & 7.67 & 7.79 & 7.97 & 7.78 & 7.6 & 7.79 & 7.84 & 7.74 & 7.69 \\
\hline 5 & 7.68 & 7.77 & 7.52 & 7.82 & 7.65 & 7.95 & 7.85 & 7.92 & 7.9 & 7.82 & 7.97 & 7.93 \\
\hline 10 & 7.63 & 7.59 & 7.47 & 7.9 & - & 7.83 & 7.76 & 7.99 & 7.71 & 7.76 & - & - \\
\hline 15 & 7.73 & - & 7.73 & 7.73 & - & 7.72 & 7.72 & - & 7.7 & 7.65 & - & - \\
\hline 20 & 7.57 & - & 7.64 & 7.68 & - & 7.65 & 7.63 & - & 7.58 & 7.58 & - & - \\
\hline 25 & 7.59 & - & 7.52 & 7.6 & - & 7.64 & 7.5 & - & - & 7.83 & - & - \\
\hline 30 & - & - & 7.54 & - & - & 7.67 & 7.79 & - & - & 7.53 & - & - \\
\hline 35 & - & - & 7.5 & - & - & 7.68 & 7.64 & - & - & - & - & - \\
\hline 40 & - & - & 7.53 & - & - & 7.72 & - & - & - & - & - & - \\
\hline \multicolumn{13}{|l|}{$\mathrm{EC}(\mu \mathrm{s} / \mathrm{cm})$} \\
\hline Yüzey & 171 & 175 & 182 & 181 & 185 & 190 & 178 & 175 & 183 & 192 & 188 & 178 \\
\hline 5 & 173 & 177 & 190 & 186 & 184 & 199 & 162 & 176 & 178 & 197 & 182 & 186 \\
\hline 10 & 178 & 183 & 189 & 185 & - & 201 & 195 & 181 & 176 & 200 & - & - \\
\hline 15 & 176 & - & 194 & 176 & - & 222 & 185 & - & 179 & 196 & - & - \\
\hline 20 & 179 & - & 191 & 171 & - & 227 & 182 & - & 180 & 194 & - & - \\
\hline 25 & 181 & - & 192 & 182 & - & 236 & 190 & - & - & 198 & - & - \\
\hline 30 & - & - & 196 & - & - & 218 & 192 & - & - & 201 & - & - \\
\hline 35 & - & - & 208 & - & - & 210 & 203 & - & - & - & - & - \\
\hline 40 & - & - & 201 & - & - & 213 & - & - & - & - & - & - \\
\hline \multicolumn{13}{|c|}{ Mangan (mg/L) } \\
\hline Yüzey & 0.04 & 0.02 & 0.02 & 0.02 & 0.04 & 0.03 & 0.03 & 0.03 & 0.03 & 0.02 & 0.02 & 0.02 \\
\hline 5 & 0.03 & 0.02 & 0.03 & 0.03 & 0.02 & 0.03 & 0.04 & 0.02 & 0.03 & 0.02 & 0.03 & 0.03 \\
\hline 10 & 0.04 & 0.03 & 0.02 & 0.03 & - & 0.02 & 0.03 & 0.02 & 0.04 & 0.03 & - & - \\
\hline 15 & 0.04 & - & 0.03 & 0.02 & - & 0.03 & 0.01 & - & 0.04 & 0.03 & - & - \\
\hline 20 & 0.04 & - & 0.03 & 0.04 & - & 0.02 & 0.02 & - & 0.03 & 0.03 & - & - \\
\hline 25 & 0.05 & - & 0.05 & 0.04 & - & 0.02 & 0.02 & - & - & 0.05 & - & - \\
\hline 30 & - & - & 0.05 & - & - & 0.05 & 0.06 & - & - & 0.08 & - & - \\
\hline 35 & - & - & 0.09 & - & - & 0.10 & 0.06 & - & - & - & - & - \\
\hline 40 & - & - & 0.12 & - & - & 0.15 & - & - & - & - & - & - \\
\hline \multicolumn{13}{|l|}{$\mathrm{Fe}(\mathrm{mg} / \mathrm{L})$} \\
\hline Yüzey & 0.01 & 0.01 & 0.01 & 0.01 & 0.02 & 0.02 & 0.01 & 0 & 0.02 & 0.01 & 0.01 & 0.01 \\
\hline 5 & 0.01 & 0.01 & 0.02 & 0.01 & 0.02 & 0.01 & 0.01 & 0.01 & 0.01 & 0.01 & 0.01 & 0.01 \\
\hline 10 & 0.02 & 0.03 & 0.03 & 0.01 & - & 0.03 & 0.01 & 0.01 & 0.01 & 0.01 & - & - \\
\hline 15 & 0.01 & - & 0.02 & 0.02 & - & 0.01 & 0.02 & - & 0.02 & 0.02 & - & - \\
\hline 20 & 0.03 & - & 0.01 & 0.03 & - & 0.02 & 0.02 & - & & 0.01 & - & - \\
\hline 25 & 0.02 & - & 0.01 & 0.01 & - & 0.02 & 0.02 & - & - & 0.02 & - & - \\
\hline 30 & - & - & 0.02 & - & - & 0.01 & 0.01 & - & - & 0.02 & - & - \\
\hline 35 & - & - & 0.02 & - & - & 0.05 & 0.01 & - & - & - & - & - \\
\hline 40 & - & - & 0.04 & - & - & - & - & - & - & - & - & - \\
\hline \multicolumn{13}{|c|}{ Nitrat (mg/L) } \\
\hline Yüzey & 0.2 & 0.4 & 0.3 & 0.2 & 0.2 & 0.2 & 0.2 & 0.3 & 0.2 & 0.3 & 0.3 & 0.4 \\
\hline 5 & 0.2 & 0.3 & 0.2 & 0.2 & 0.2 & 0.2 & 0.2 & 0.2 & 0.3 & 0.3 & 0.3 & 0.2 \\
\hline 10 & 0.2 & 0.2 & 0.2 & 0.2 & - & 0.2 & 0.2 & 0.1 & 0.2 & 0.2 & - & - \\
\hline 15 & 0.1 & - & 0.1 & 0.1 & - & 0.1 & 0.2 & - & 0.1 & 0.2 & - & - \\
\hline
\end{tabular}




\begin{tabular}{lllllllllllll}
$\mathbf{2 0}$ & 0.1 & - & 0.2 & 0.2 & - & 0.2 & 0.2 & - & 0.2 & 0.2 & - & - \\
$\mathbf{2 5}$ & 0.2 & - & 0.2 & 0.2 & - & 0.1 & 0.2 & - & - & 0.2 & - & - \\
$\mathbf{3 0}$ & - & - & 0.1 & - & - & 0.2 & 0.1 & - & - & 0.2 & - & - \\
$\mathbf{3 5}$ & - & - & 0.2 & - & - & 0.2 & 0.1 & - & - & - & - & - \\
$\mathbf{4 0}$ & - & - & 0.1 & - & - & - & - & - & - & - & - & - \\
\hline
\end{tabular}

Tablo 1 de görüldüğü gibi barajın farklı noktasında ve farklı derinliklerinde $\mathrm{Fe}, \mathrm{Mn}$ ve NO3 değerleri çok düşük olup önemli bir değişim göstermemektedir. NO3, çevrede doğal olarak bulunur ve önemli bir bitki besinidir. Tarımsal faaliyetlerden, katı atık sızıntı sularından, endüstriyel deşarjlardan ve atıksu deşarjı ile septik tanklar da dâhil olmak üzere insan ve hayvan dışkılarındaki azotlu atıkların oksidasyonu sonucu yerüstü ve yer altı sularına ulaşabilir [21].

Nitrat, vücut içinde nitrit formuna döner ve sağlığa olumsuz etkisi olabilecek iki kimyasal reaksiyona uğrayabilir. Özellikle altı aylık ve daha küçük bebeklerde mavi bebek sendromuna (methemoglobinemia) ve nitrosamit/nitrosamin formlarına dönüşerek muhtemel kanserojenik etkiye sebep olabilir [22].

Doğal tatlı su kaynaklarındaki Fe konsantrasyonu 0,5-50 $\mathrm{mg} / \mathrm{L}$ arasında değişen değerlerde bulunabilir [23]. İçme suyu kaynaklarında, demir (II) tuzları kararsız yapıda olup, çözünmeyen demir (III) hidroksit formuna geçerek, pas rengi silt şeklinde çöker. Demir, özellikle demir (II) oksit durumundayken, insan vücudu için gerekli elementlerden biridir.

Demir, $3 \mathrm{mg} / \mathrm{L}$ ve üzerine çıkmadığı takdirde insan sağlığına olumsuz etkisi bulunmamaktadır. Ancak tat eşik değerinin bu değerin çok altında kalması sebebiyle insan sağlığı açısından limit değer önerilmemiştir. Mangan, yerküre yapısında en çok bulunan metallerden biridir, genellikle demirle birlikte görülür. Ancak sudaki konsantrasyonları demire oranla daha düşüktür.

Ham suda genellikle 0,001-0,6 mg/L aralığında bulunmakla birlikte; $1 \mathrm{mg} / \mathrm{L}$ 'yi aşan konsantrasyonlarda, manganlı minerallerin oksijensiz ortamda suyla teması ya da bakterilerin aktivitesi söz konusudur [24]. 0,1 mg/L değerini aşan konsantrasyonlarda istenmeyen tat ile borularda ve çamaşırlarda lekelere neden olur. $0,02 \mathrm{mg} / \mathrm{L}$ gibi düşük konsantrasyonlarda su borularında tabaka oluşturabilir, bu da zamanla siyah çökelti halinde birikme yapabilir. Pek çok ülke, renk değişimiyle birlikte gelen sorunlar sebebiyle, mangan için $0,05 \mathrm{mg} / \mathrm{L}$ standart değer belirlemiştir [23]. Bu çalıșma belirlenen $\mathrm{Mn}$ değeri $0.02-0.1 \mathrm{mg} / \mathrm{L}$ arasında değişmektedir (Tablo 1). Elektriksel iletkenlik (kondüktivite), suyun elektrik akımını iletebilme özelliğinin sayısal olarak ifadesidir. $\mathrm{Su}$ analiz sonuçları verilirken mikrosiemens $/ \mathrm{cm}(\mu \mathrm{S} / \mathrm{cm})$ cinsinden $25^{\circ} \mathrm{C}$ sicaklıktaki değeri hesaplanarak belirtilir. Suların elektriksel iletkenliği, iyonların suda varlığına, toplam derişimine, hareketliliklerine (mobilite), değerliklerine, göreli değișimlerine ve sıcaklığa bağlıdır. Sıcaklık artışı ile suların elektriksel iletkenlikleri de artar [25]. Sudaki iyonların derişimi arttıkça elektriksel iletkenlik de artar, dolayısıyla elektriksel iletkenlik ölçümleri sudaki toplam iyon derişimi hakkında iyi bir gösterge oluşturur [26]. Doğal haldeki yüzey sularının elektriksel iletkenliği $50-1500 \mu \mathrm{S} / \mathrm{cm}$ arasında değişir [27]. İletkenliğin insan sağlığ1 üzerinde, içme suyu tüketimi yoluyla bağlantılı bir etkisinin olduğuna dair bir veri bulunmamaktadır [28].

$\mathrm{Bu}$ çalışma da EC değerinde de önemli bir değişim olmadığı görülmektedir. Derinlere inildikçe EC değerinde bir miktar artış gözlenmiştir (Tablo 1).pH sudaki hidrojen iyonu konsantrasyonu ölçüsüdür ve sudaki asit ve bazlar arasındaki dengeyi gösterir. Suların pH'i hidrojen iyonu üreten veya oluşturan birbirleri ile ilișkili kimyasal reaksiyonlar tarafindan kontrol edilir. Doğal yeraltı sularının $\mathrm{pH}^{\prime} 16.0-8.5$ arasında değişir, fakat termal sularda düşük $\mathrm{pH}$ değerleri de görülebilir.

Kirlenmemiş suların pH'ı 6.5-8.5 arasındadır [25]. Yerüstü Su Kalitesi Yönetmeliği Ek-5 Tablo 2'de [29] verilen "Kitaiçi Yerüstü Su Kaynaklarının Genel kimyasal ve fizikokimyasal parametreler açısından Sınıflarına Göre Kalite Kriterlerinde yerüstü su kütlelerinin tüm sınıflarında yüzey suyu $\mathrm{pH}$ değerinin $6-9$ arasında bir değere sahip olması gerektiğibelirtilmiştir. Bu çalışmada, baraj göl alanındaki tüm noktalarda $\mathrm{pH}$ 7.5-8 arasında ölçülmüştür [30] (Kalıpçı ve ark., 2017).

Farklı noktalarda ölçülen sıcaklıkla ilgili mekânsal dağılım haritası Şekil 3'de görülmektedir. 

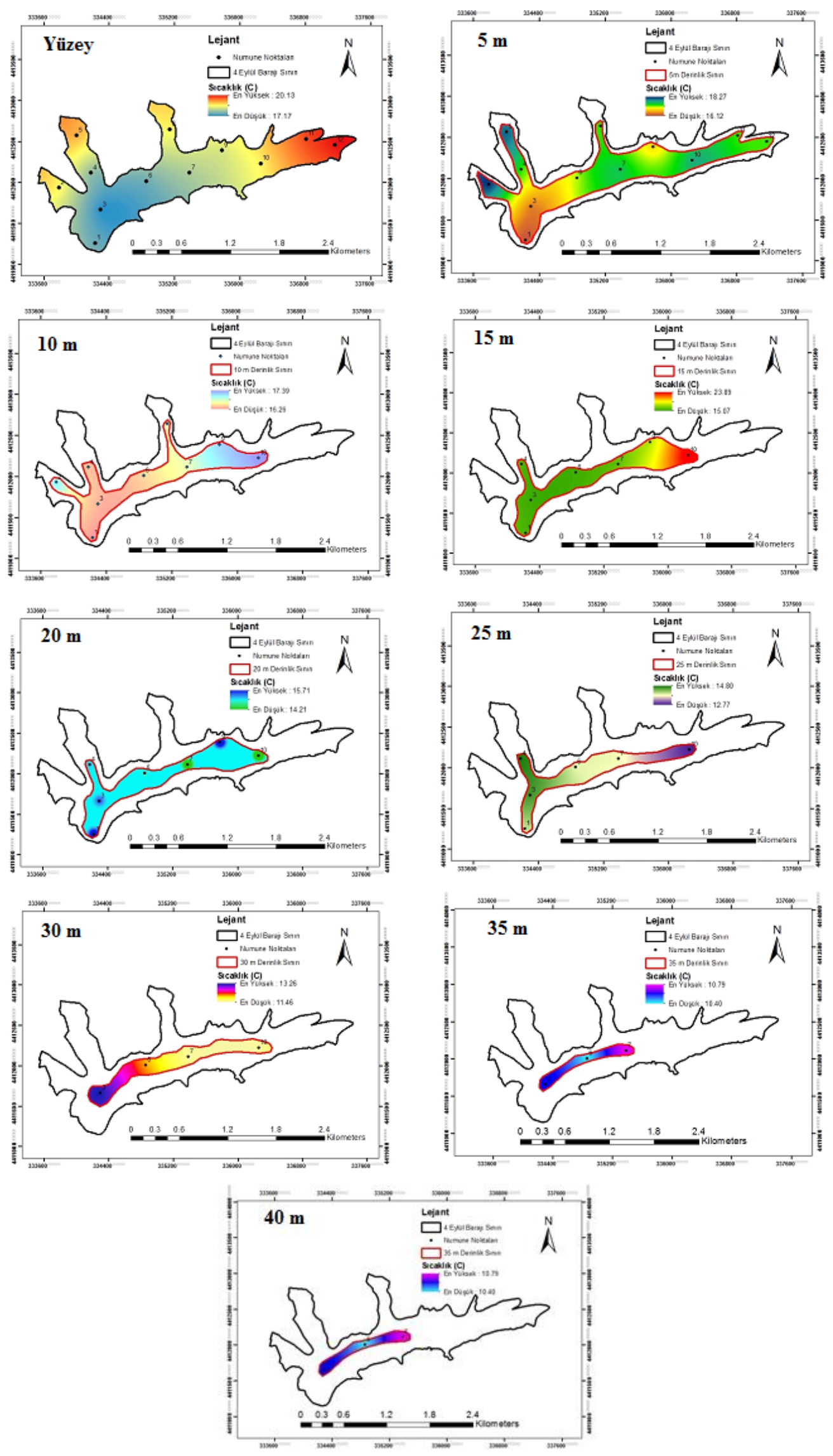

Şekil 3. Farklı derinliklerdeki sıcaklık değişimi mekânsal dağılım haritası 

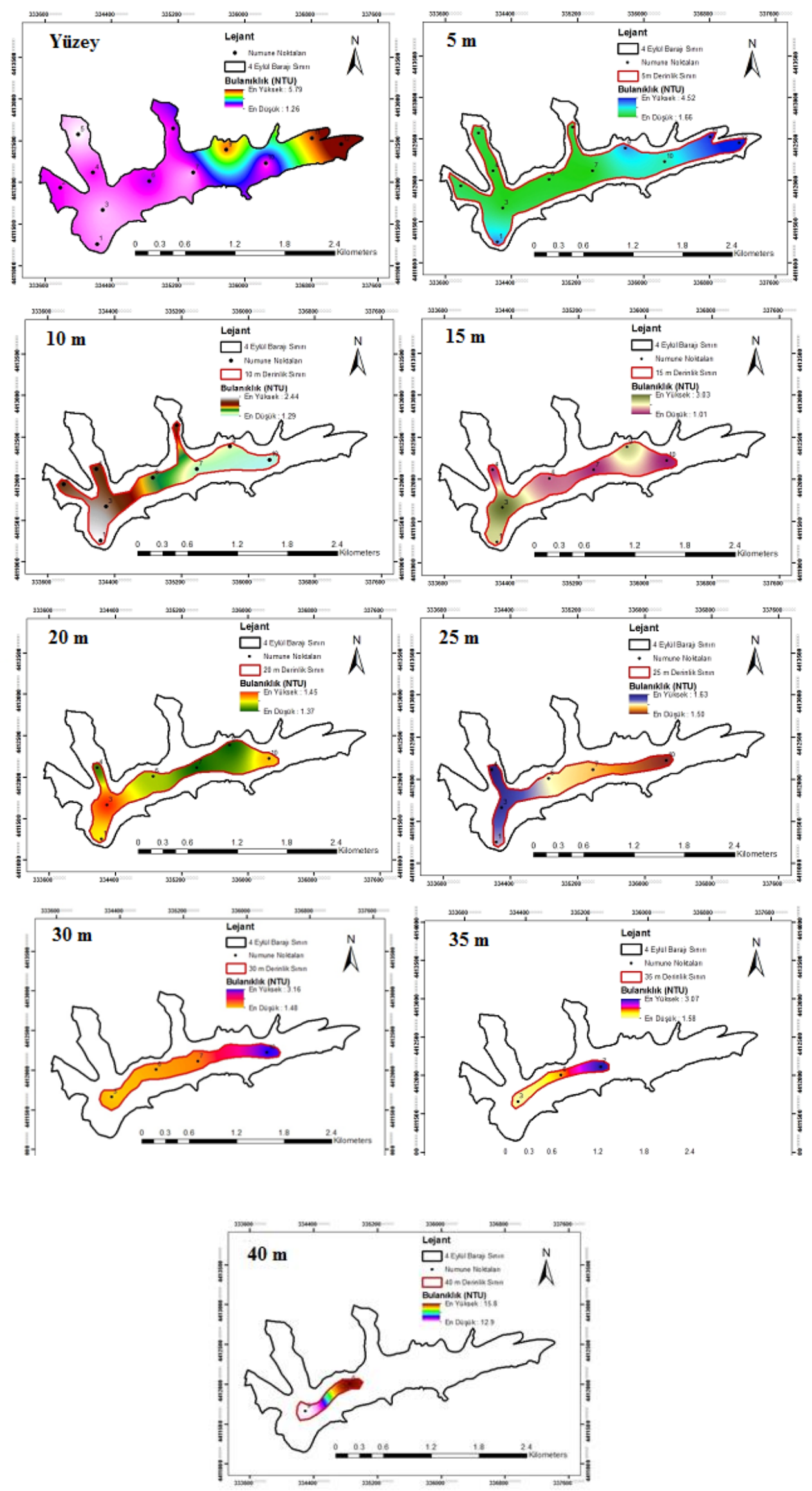

Şekil 4. Farklı derinliklerdeki bulanıklık değişimi mekânsal dağılım haritası 

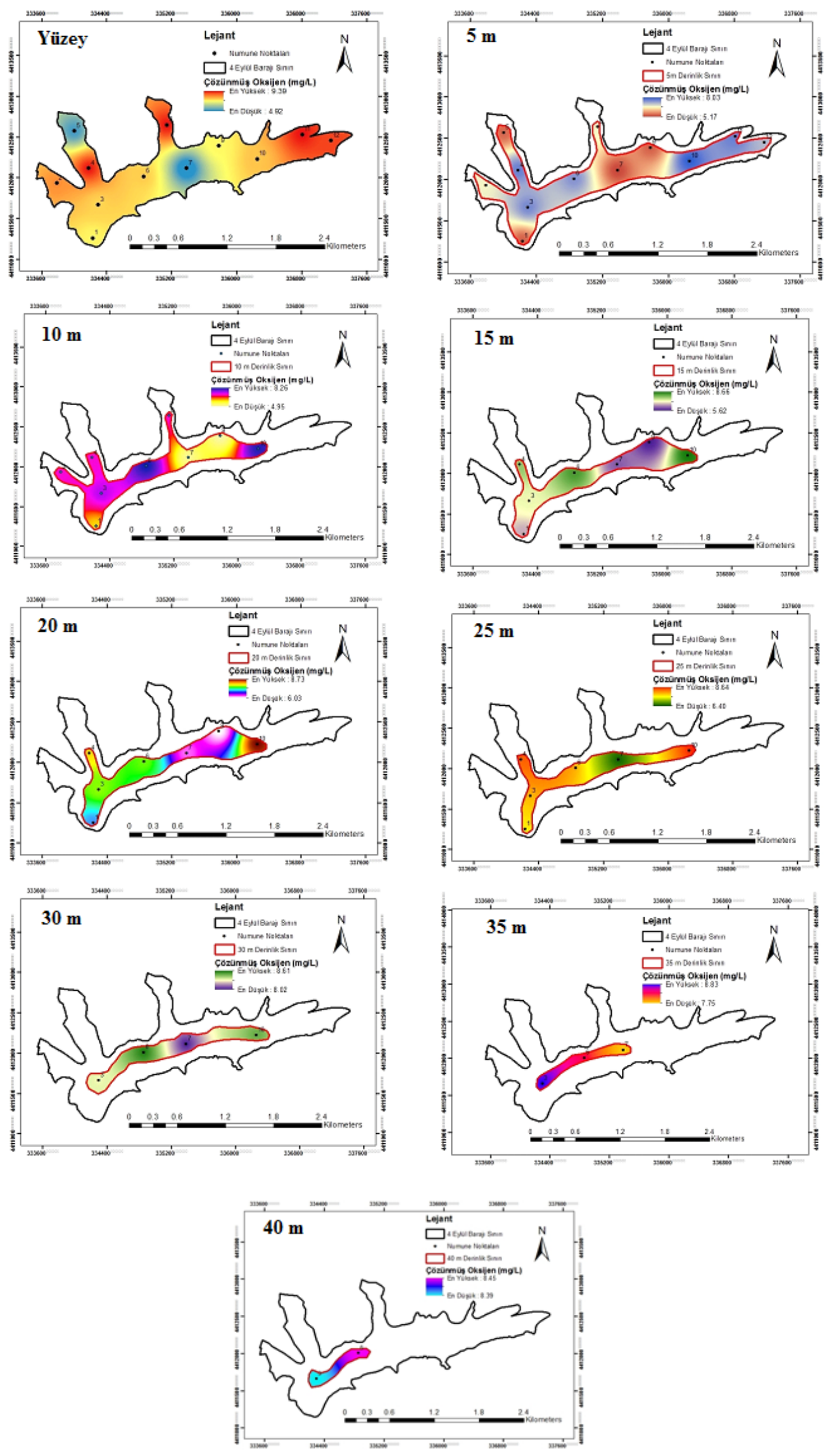

Şekil 5. Farklı derinliklerdeki Ç.O değişimi mekânsal dağılım haritası 

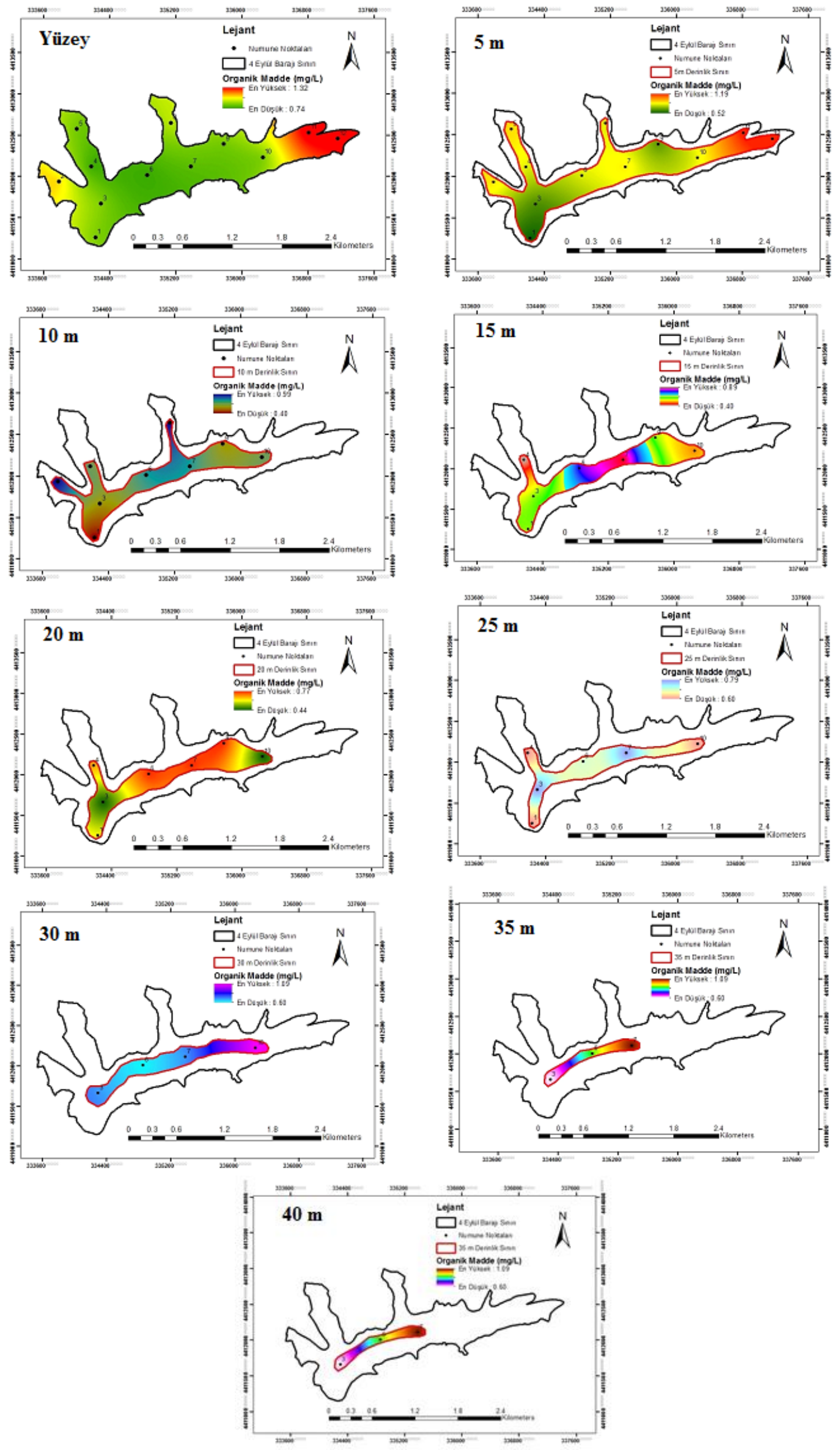

Şekil 6. Farklı derinliklerdeki organik madde değişimi mekânsal dağılım haritası 
Sıcaklık organizmaların sulardaki dağılımını etkilemektedir. Çünkü sıcaklık sucul organizmaların tüm yaşamsal aktivitelerini etkileyerek fizyolojilerinin değişmesine sebep olur.

Su ortamındaki fiziksel, biyolojik ve kimyasal süreçler sıcaklığın etkisi altındadır. Yüksek sıcaklık birçok kimyasal bileşiğin çözünürlüğünü arttırarak kirleticilerin sudaki canlı yaşamı üzerindeki etkilerini çoğaltır. Suların mikrobiyolojik karakteristikleri, sicaklı̆ğın mikroorganizmaların büyüme ve yaşama süreleri üzerindeki kontrolü nedeni ile sıcaklığa bağımlıdır. Sıcaklık artı̧̧ı ile sulara uygulanan dezenfeksiyonun etkenliği artar [31]. $\mathrm{Bu}$ çalışmada, baraj yüzeyinde sıcaklık 17-20 C0 arasında değişmiştir. Derinlere inildikçe sıcaklıkta azalma gözlenmiş olup baraj diplerinde sicaklık 10-22 C0'ye düşmüştür. Bu durum diğer çalışmalar ile benzerlik göstermektedir [32]. Çalışma yaz ayında gerçekleştiği için yüzey suyunun sıcaklığının yüksek olması beklenen bir durumdur. Ayrica sicaklik barajin kenarlarında orta kısma oranla daha yüksek değerde ölçülmüştür.

Farklı derinliklerdeki bulanıklık, Ç.O ve organik madde parametrelerine ait mekânsal dağılım haritaları sırasıyla Şekil 4, Şekil 5 ve Şekil 6'da verilmiştir.

İçme suyunun ÇO konsantrasyonu genellikle yeterlidir ancak derin depolardan çekilmesi, şebekede kayda değer oranda mikroorganizma gelişiminin olması ya da uzun süreli yüksek su sıcaklığının söz konusu olması halinde, içme suyundaki oksijen konsantrasyonları düşebilmektedir

Düşük oksijen konsantrasyonların da veya anoksik koşullarda, istenmeyen anaerobik mikroorganizma gelişimi sebebiyle, suyun estetik kalitesinin olumsuz etkilenmesinin yanı sıra boru ve tesisatlardaki korozyon da artış göstermektedir. $\mathrm{Bu}$ mikroorganizmalardan, mangan indirgeyen bakteriler siyah mangan tortuları üreterek borularda birikme ve çamaşırlarda lekelenmeye sebep olabilmektedir [33].

Bu çalışma da baraj göl alanında derinliğe bağlı olarak Ç.O açısından önemli bir değişim gözlenmemiştir. Derinlere inildikçe Ç.O değerinde bir miktar artış gözlenmiştir. Ayrıca barajı besleyen derelerin baraja giriş kısımlarında Ç.O değeri barajın orta kısımlarına göre daha yüksektir (Şekil 5) Bu durum oksijence zengin derelerin baraja taşıdığı Ç.O'den kaynaklanmaktadır. Kirlenmemiş doğal sularda çözünmüş oksijen konsantrasyonu genellikle 10 $\mathrm{mg} / \mathrm{L}$ civarındadır. Oksijen konsantrasyonu 5 $\mathrm{mg} / \mathrm{L}$ 'nin altına düştüğünde biyolojik toplulukların yaşam fonksiyonları olumsuz etkilenmektedir. . Baraj göl alanında Ç.O miktarı ortalama $7-9 \mathrm{mg} / \mathrm{L}$ arasında ölçülmüştür ve bu değer benzer çalışmalar ile uyumludur [34].

İçme suyunun klor ile dezenfeksiyonu trihalometan (THM) ve haloasetik asit (HAA) gibi dezenfeksiyon yan ürünlerinin (DYÜ) oluşumuna neden olmaktadır [35]. Dolayısıyla, sudaki doğal organik maddeler, THM ve HAA oluşumu için olası bir öncü bileşik görevi üstlenmektedir. Klorlanmış içme suyu içinde oluşan doğal organik maddeler arasında THM ve HAA'ler 1970'lerden beri en fazla çalışılan ve kanserojen yapabilme özelliği açısından en şüpheli görülen DYÜ türleridir [36]. Çalışma kapsamında yapilan analizlerde organik madde miktarı $0.4-1 \mathrm{mg} / \mathrm{L}$ arasında belirlenmiş̧ir. Ayrıca barajın kıyı bölgelerinde ve daha derin kısımlarında organik madde miktarı bir miktar daha yüksek bulunmuştur (Şekil 6).

Bulanıklık değerlerinde ise büyük farklılıklar bulunmamıştır. Sadece barajın dip kısımlarından alınan numunelerin bulanıklık miktarı beklendiği şekilde yüksek çıkmıştır. Baraj su alma yapısı dip kısımın yaklaşık 19 m yukarısındadır. Dolayısıyla artıma tesisine alınan suda bu durum olumsuzluk oluşturmamaktadır. Dipte oluşan çökelme ve hareketlilik bulanıklık değelerini artırmaktadır.

\section{SONUÇ}

$\mathrm{Bu}$ çalışmada; Sivas kentinin içme suyu ihtiyacının karşılandığı 4 Eylül Barajı'nın 12 farklı noktasında her 5 m'de bir numune alınmıştır. Bu numunelerde sıcaklık, EC, Ç.O, $\mathrm{pH}$, bulanıklık, $\mathrm{Mn}, \mathrm{Fe}, \mathrm{NO} 3$ ve organik madde analizleri yapılmıştır. $\mathrm{Bu}$ analizler ile birlikte barajda seviyeye bağlı su kalitesi belirlenmiştir. Elde edilen analiz sonuçları, CBS'nin analiz yöntemlerinden olan Kriging enterpolasyon yöntemi ile değerlendirilmiş ve barajın farklı derinliklerindeki su kalitesine ait mekânsal dağılım haritaları oluşturulmuştur. Çalışmada; baraj göl alanında yüzeyden derinlere inildikçe mangan değerinin arttı̆̆, Fe değerinde ise önemli bir değişikliğin görülmedi belirlenmiştir. Göl suyunda organik madde miktarı yüzeyde çok fazla iken belli bir derinlikten sonra çok fazla değişmemektedir. $\mathrm{pH}$ değerinin de derinliğe bağl1 olarak değişim göstermediği belirlenmiştir. Sudaki NO3 değerleri $0.1-0.3 \mathrm{mg} / \mathrm{L}$ arasında değişirken çözünmüş oksijen değerlerinde önemli bir değişiklik gözlenmemiştir. Amca bulanıklık değeri gölün tabanına doğru oldukça artmıştır. EC 
değeri ise göl kenarlarında orta kısma göre daha yüksek değerlerde ölçülmüştür.

\section{KAYNAKÇA}

[1] Ö. Fakıoğlu, M. Atamanalp, N. Demir, "Baraj Göllerinde Toksik Mavi Yeşil Algler”, Ankara Üniversitesi Çevre Bilimleri Dergisi, Cilt: 3, no 2. Pp. 65-71, 2011.

[2] A. Kurnaz, E. Mutlu, Uncumusaoğlu, A. "Determination of Water Quality Parameters and Heavy Metal Content in Surface Water of Çiğdem Pond (Kastamonu/Turkey)", Turkish Journal of Agriculture - Food Science and Technology, 4(10), 907-913. 2016.

[3] N. Polat, T. Akkan, "Assessment of Heavy Metal and Detergent Pollution in Giresun Coastal Zone, Turkey", Fresenius Environmental Bulletin, 25(8), 2884-2890. 2016.

[4] C. Nilsson, C. Reidy, M. Dynesius, C. Revenga, "Fragmentation and flow regulation of the world's large river systems" Science 308, pp. 405-408, 2005.

[5] M. Burke, K. Jorde, J. Buffington, "Application of a hierarchical framework for assessing environmental impacts of dam operation: changes in streamflow, bed mobility and recruitment of riparian trees in a western North American river", Journal of Environmental Management 90, pp. 224-236, 2009.

[6] C. Bratrich, B. Truffer, K. Jorde, J. Markard, W.Meier, A. Peter, M. Schneider, B. Wehrli, "Green hydropower: a new assessment procedure for river management", River Research and Applications 20, pp. 865-882, 2004.

[7] K. Ha, M. Jang, G. Joo, "Winter Stephanodiscus bloom development in the Nakdong River regulated by an estuary dam and tributaries", Hydrobiologia 506/509, pp. 221-227. 2003.

[8] A. Ünlü, F. Çoban, S.M. Sara Tunç, "Hazar Gölü su kalitesinin fiziksel ve inorganik-kimyasal parametreler açisindan incelenmesi”, J. Fac. Eng. Arch. Gazi Univ. Cilt 23, No 1, pp. 119-127. 2008.

[9] F. Turan, ve G. Ülkü, "Gökpınar ve Çürüksu Çaylarının kirlilik parametre ve yüklerinin izlenmesi”, Pamukkale Üniversitesi Mühendislik Bilimleri Dergisi, 19(3), 133-144. 2012.

[10] E. Alp. SWAT (The Soil And Water Assessment Tool) Teori ve Örnek Uygulama. T.C. Orman ve Su İşleri Bakanlığı. Teorik ve Uygulamalı Havza Modellemesi Eğitimi. 2015.

[11] A.L. Heathwaite, P.F. Quinn, and C.J.M. Hewett. "Modelling and managing critical source areas of diffuse pollution from agricultural land using flow connectivity simulation", Journal of Hydrology, 304(1), 446-461. 2005.
[12] F. Yılmaz, "Mumcular Baraj1 (MuğlaBodrum)' nın Fiziko-Kimyasal Özellikleri”, Ekoloji 13 (50), pp. 10-17. 2004.

[13] Alaş, A. "Kayaboğazı (Tavşanl1-Kütahya) Baraj Gölünde Yaşayan Leuciscus cephalus L.1758 ve Tinca tinca (L., 1758)'nın BiyoEkolojisi Üzerine Bir Araştırma", Doktora Tezi, Gazi Üniversitesi, Fen Bilimleri Enstitüsü, Ankara.1998.

[14] P.T. Srinivasan, and T. Viraraghavan, "Characterization and Concentratio Profile of Aluminum during Drinking-Water Treatment", Water SA, 28(1), pp. 99-106, 2002.

[15] S. Savcı, MC. Bağdatlı. "İçme Sularındaki Bazı Ağır Metallerin (Ni, Mn, Cu) CBS Yardımıyla Mekansal Analizleri: Türkiye'nin Anadolu Bölgesinden Örnek Bir Çalışma", Uluslar. Hakemli Müh. ve Fen Bil. Der.,4, 65-78. 2015.

[16] S. Yıldız, and M. Değirmenci, "Sivas 4 Eylül Baraj1 ve Kollarındaki Su Kalitesinin İncelenmesi”, 9 Eylül Üniversitesi Mühendislik Fakültesi Mühendislik Bilimleri Dergisi, cilt 13, no 2. pp. 37-46. 2012.

[17] Standart Methods. Standart Methods for the Examination of water and Wastewater, 17th edition, American Public Health Association (APHA) American Water Works Association (AWWA), Water Pollution Control Fedarition (WPCF), Washington-USA. 1998.

[18] ESRI. ArcMap 10.1 Spatial Analiz (213 p), Esri Bilgi Sistemleri Mühendislik ve Eğitim Ltd. Şti. Ankara. 2014.

[19] P.K. Sharma, R. M.P. Vijay, "Punia Geostatistical evaluation of groundwater quality distribution of Tonk district, Rajasthan", International Journal Of Geomatics and Geosciences, 6 (2), pp. 1474-1485, 2015.

[20] ESRI, ArcMap 10.1 Help File, http://resources.arcgis. com/en/help/main/10.1/, 2015. Erişim zamanı Ocak, 11, 2017.

[21] N.F. Gray, Drinking Water Quality Problems and Solutions . (2nd edition). New York: Cambridge University Press. 2008.

[22] AWWA. Water Quality and Treatment - A Handbook on Drinking Water. (6th edition) ABD: Mc Graw Hill, 2011.

[23] World Health Organization-WHO. Guidelines for Drinking Water Quality. 4th edn. Geneva: World Health Organization. 2011.

[24] J. DE Zuane, Handbook of Drinking Water Quality. (2nd edition). ABD: John Wiley \& Sons Inc. 1990.

[25] J.D. Hem, Study and interpretation of the chemical characteristics of natural water: U.S. Geological Survey Water- Supply Paper 2254, U.S. Geological Survey, Alexandria, VA 22304, USA, p.263, 1985. 
[26] B.A. Day, H.I. Nightingale, "Relationships between groud- water silica, total dissolved solids, and specific electrical conductivity", Ground Water, 22(1), pp. 80- 85, 1984.

[27] R.N. McNeely, V.P. Neimanis, L. Dwyer, "Water Quality Sourcebook- A Guide To Water Quality Parameters: Inland Waters Directorate, Water Quality Branch", Ottowa, Canada, p. 88, 1979.

[28] World Health Organization-WHO. Manganese in Drinking-water Background document for development of WHO Guidelines for Drinking-water Quality. Geneva: World Health Organization. 2011.

[29] Yerüstü Su Kalitesi Yönetmeliği, Resmi gazete, 10 Ağustos 2016 tarih, sayı: 29797.

[30] E. Kalıpc1, H. Cüce, S. Toprak. "Damsa Barajı (Nevşehir) Yüzey Suyu Kalitesinin Coğrafi Bilgi Sistemi ile Mekansal Analizi”, Karaelmas Fen ve Müh. Derg. 7(1), 312-319. 2017.

[31] H.H. Stevens, J.F. Ficke, G.F. Smoot, Water Temperature- İnfluential Factors, Field Measurement And Data Presentation: Techniques Of WaterResources Investigations Of The United
States Geological Survey, Chapter D1, Book 1, 65p. 1975.

[32] M. Küçükyılmaz, G. Uslu, N. Birici, N.G. Örnekçi, N. Yıldız, T. Şeker. "Karakaya Baraj Gölü Su Kalitesinin İncelenmesi”, Yunus Araştırma Bülteni, 2, 145-155. 2017.

[33] National Health and Medical Research Council. Australian guidelines to reduce health risks from drinking alcohol. Canberra: NHMRC, 2009.

[34] M. Varol, "Dicle Baraj Gölü Su Kalitesinin $\mathrm{Su}$ Kirliliği Kontrolü Yönetmeliği’ne Göre Değerlendirilmesi”, Türk Tarım ve Doğa Bilimleri Dergisi 2(1): 85-91. 2015.

[35] G. Crozes, P. White, and M. Marshall, "Enhanced coagulation: it's effect on NOM removal and chemical costs", Journal of American Water Works Association, 87, pp. 7889, 1995.

[36] E.M. Vrijenhoek, A.M. Childress, M. Elimelech, T.S. Tanaka, and M.D. Beuhler, "Removing particles and THM precursors by enhanced coagulation", Journal of American Water Works Association, 90, pp. 139-150. 1998. 